\title{
Christhard Hoffmann (éd.), Preserving the Legacy of German Jewry. A History of the Leo Baeck Institute, 1955-2005
}

Tübingen, Mohr Siebeck, 2005, 474 p.

\section{Régine Azria}

\section{OpenEdition}

\section{Journals}

\section{Electronic version}

URL: http://journals.openedition.org/assr/24570

DOI: 10.4000/assr.24570

ISSN: $1777-5825$

\section{Publisher}

Éditions de l'EHESS

\section{Printed version}

Date of publication: 30 December 2012

Number of pages: 204

ISSN: 0335-5985

\section{Electronic reference}

Régine Azria, «Christhard Hoffmann (éd.), Preserving the Legacy of German Jewry. A History of the Leo Baeck Institute, 1955-2005», Archives de sciences sociales des religions [Online], 160 | octobredécembre 2012, Online since 14 March 2013, connection on 21 September 2020. URL : http:// journals.openedition.org/assr/24570; DOI : https://doi.org/10.4000/assr.24570

This text was automatically generated on 21 September 2020.

(c) Archives de sciences sociales des religions 
Christhard Hoffmann (éd.), Preserving the Legacy of German Jewry. A History of the Leo Baeck Institute, 1955-2005

Tübingen, Mohr Siebeck, 2005, 474 p.

Régine Azria

\section{REFERENCES}

Christhard Hoffmann (éd.), Preserving the Legacy of German Jewry. A History of the Leo Baeck Institute, 1955-2005, Tübingen, Mohr Siebeck, 2005, 474 p. 
1 Preserving the Legacy of German Jewry doit sa publication (en 2005) au cinquantième anniversaire de l'Institut Leo Baeck (ILB), lequel a été fondé en 1955 à Jérusalem. L'histoire de cet Institut, ainsi nommé en hommage à son fondateur, est indissolublement liée à celle des Juifs chassés d'Allemagne par la montée puis l'avènement du nazisme au début des années 1930. Au lendemain de la guerre, dispersés entre les États-Unis, l'Angleterre et Israël, ces Juifs émigrés s'étaient donné pour tâche de conserver la mémoire du monde juif germanophone qui venait de disparaitre. Il s'agissait pour eux de préserver un héritage culturel dynamique et pluriel, bien conscients néanmoins que le judéocide avait irrémédiablement porté atteinte à l'idée de la "symbiose judéo-allemande » dont cet héritage serait le legs. Nombre d'entre eux ne pouvaient se résigner à renoncer à cette idée de symbiose, quand bien même elle était violemment contestée et dénoncée par d'autres, notamment par Gershom Scholem, le grand historien de la mystique juive.

Aussi, les contributeurs se livrent-ils à un retour critique et autoréflexif sur cette «rencontre» judéo-allemande et en relèvent les évidentes contradictions: son caractère émancipateur, l'intégration, le renouveau juif d'un côté; l'ostracisme, l'antisémitisme, les persécutions, le tout culminant avec la solution finale de l'autre. Les émigrants judéo-allemands porteurs de cette mémoire entendaient transformer celle-ci en histoire et, pour ce faire, ils s'en sont remis à des historiens dont la compétence était reconnue. Cinquante ans après sa fondation, l'ILB, dont la liste des publications occupe vingt pages en fin d'ouvrage, peut se targuer d'avoir rempli sa triple mission (constitution de collections, recherche historiographique, publications). Dans cette liste impressionnante se trouvent réunis les noms des représentants les plus illustres de l'intelligentsia judéo-allemande entre 1955 et 2004.

3 Les trois localisations de l'ILB - Jérusalem, New York et Londres - étaient loin d'être neutres quant à leurs effets. Le poids du lieu, de son histoire, de la nature des relations passées et/ou présentes avec les Juifs, des idées qui circulaient dans les milieux académiques et intellectuels, a considérablement influencé les Juifs immigrés de l'ILB et l'impact de ces facteurs s'est fait sentir sur leurs «idéologies » respectives. Ainsi, les Juifs allemands de sensibilité sioniste établis à Jérusalem ont-ils dû apprendre à gérer la tension entre la jeune historiographie juive officielle du pays, sioniste et nationale, et leur volonté de préserver la mémoire et l'image positive du judaïsme allemand d'avant la catastrophe. Alors que pour ceux de New York, la transplantation vers une Amérique neutre et multiculturelle leur permettait d'entretenir sans complexe l'ambiance du passé, d'en perpétuer la mémoire et de préserver ainsi cette culture judéo-allemande à laquelle ils restaient profondément attachés malgré les vicissitudes de l'histoire. Quant à l'Institut de Londres, il allait être le creuset d'une nouvelle discipline universitaire : l'historiographie de la modernité judéo-allemande.

4 On aura remarqué l'absence d'une branche allemande de cet Institut, ce qui n'aurait a priori rien d'étonnant en soi. Pas si évident pourtant, au vu de la renaissance de la vie 
juive qui s'y donne à voir depuis la chute du mur de Berlin et la réunification des deux Allemagne. Les Juifs, nous le savons, font retour vers l'Allemagne et ils s'attachent à réinscrire les signes tangibles d'une présence juive dans les lieux et, plus encore à y implanter une mémoire juive. Aussi, est-ce très logiquement à Berlin que, depuis l'ouverture du Musée juif en 2001, les dirigeants de l'ILB ont convenu d'entreposer leur fonds documentaire, un fonds constitué par les microfilms des Archives de New York.

Nous avons affaire ici à une sorte de mise en abîmes: la recherche sur les Juifs d'Allemagne se mue en une recherche sur l'histoire de l'ILB. Cette histoire de l'ILB occupe la première partie de l'ouvrage. Outre la question très controversée de la " symbiose ", deux questions sensibles ont mobilisé les collaborateurs de l'ILB ; celle de l'assimilation des Juifs allemands, à propos de laquelle trois courants d'interprétation s'affrontent : ceux qui y voient une trahison; ceux qui y voient une fatalité ; ceux enfin qui, plutôt que d'y voir un abandon et une perte d'identité, la considèrent comme une ouverture et un renouvellement. L'autre question sensible est celle de l'auto-défense juive et les activités de la résistance juive face à l'antisémitisme nazi dont l'ILB a fait un de ses secteurs de recherche privilégiés, le souci de ses membres étant d'apporter un démenti argumenté et documenté à l'idée largement répandue de la passivité juive.

Comparable à un entrelacs de spirales, le caractère diasporique de cette émigration judéo-allemande peut se lire comme une autre forme de mise en abîme où l'on voit ce qu'il reste de ce fragment allemand de la diaspora juive globale se fractionner et se diasporiser à son tour et où l'effet réseau auquel donne lieu la circulation de ses membres et de leurs productions intellectuelles entre leurs implantations israélienne, étasunienne et britannique, s'incarne dans un Institut territorialement éclaté, dédié à une triple mission archivistique, mémorielle et historiographique. 